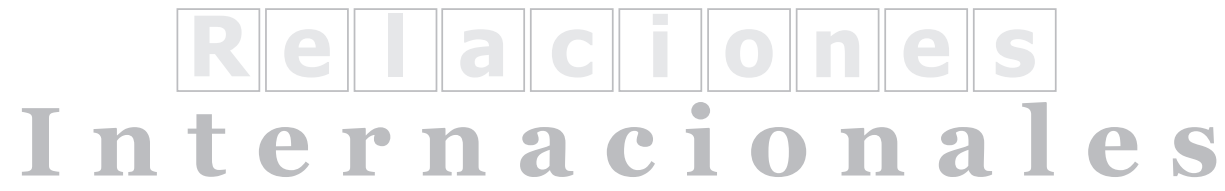





\title{
El rol de Alemania en el marco de la cooperación binacional sobre el proceso de Justicia y Paz en Colombia*
}

\author{
The Role of Germany in the Framework of the \\ Bilateral Cooperation on Justice and Peace \\ Process in Colombia
}

\author{
Marco Antonio Macana ${ }^{* *}$ \\ Andrés Mauricio Valdivieso ${ }^{* * *}$
}

Recibido: 11/o8/2013

Aprobado Evaluador Interno: 18/12/2013

Aprobado Evaluador Externo: 01/02/2014

\begin{abstract}
Resumen
Este artículo examina el papel de Alemania como un actor fundamental en el marco de cooperación interregional para la implementación de la Ley de Justicia y Pazy en general sobre el proceso de paz en Colombia. Así pues se parte de la descripción de los principios orientadores de la política exterior alemana. Igualmente, se realiza un esbozo de los principales programas de cooperación alemanes que han sido creados e implementados en Colombia a partir de las experiencias de transición de las dictaduras nazi y comunista
\end{abstract}

\begin{abstract}
This paper examines the role of Germany as a key player in the regional cooperation framework for the implementation of the Justice and Peace Law and, in general, on the peace process in Colombia. Therefore, it starts with the description of the guiding principles of German foreign policy. Also, an outline of the main cooperation programs that have been created and implemented in Colombia from transition experiences of Nazi and Communist dictatorships towards peace and democracy is made. Finally, it concludes that
\end{abstract}

doi:10.11144/Javeriana.PAPO19-1.ramc

* Artículo de Revisión.

** Abogado de la Universidad Santiago de Cali, Colombia., Magister en Criminología Ciencias Penales y Penitenciarias. Director del Centro de Estudios e Investigaciones de la Facultad de Derecho de la USC. Integrante del Grupo de investigación Gicpoderi de la USC. Profesor Universitario. Correo: macana2311@hotmail.com

*** Abogado de la Facultad de derecho de la USC. Joven Investigador de Colciencias. Miembro del Grupo de Investigación en Problemas Contemporáneos del Derecho y la Política -Gipcodep- de la Universidad San Buenaventura Cali. Director de Programa de Derecho y de Gobierno y Relaciones Internacionales de la Facultad de Derecho y Ciencias Políticas de la Universidad de San Buenaventura - Cali-Valle. amvaldivieso@usbcali.edu.co 
hacia la paz y democracia. Finalmente, se concluye que Alemania, de acuerdo con su política internacional, fomenta una salida negociada al conflicto armado y en ese sentido se ha ocupado de consolidar proyectos de cooperación y apoyo a Colombia, los cuales se han convertido en herramientas trascendentales no sólo para la aplicación de la Ley de Justicia y Paz sino también para construir un escenario de paz duradera.

\section{Palabras clave:}

justicia transicional; cooperación; conflicto armado; paz
Germany, according to its foreign policy, encourages a negotiated solution to the armed conflict and in that sense has been consolidating cooperation projects and support for Colombia, which have become transcendental tools not only for the implementation of the Justice and Peace Law, but also to build a lasting peace scenario.

\section{Keywords:}

transitional justice; cooperation; armed conflict; peace 


\section{La UE y Alemania desde sus directrices y principios de cooperación con miras a la solución política del conflicto colombiano}

La cooperación es una estrategia que posee características propias del compromiso alemán con otras naciones, pues procura conseguir logros sostenibles por medio de la colaboración recíproca y el cubrimiento de muchos ámbitos. Sus actores u organizaciones, aunque con una visión distinta o de rivalidad, gozan de algo en común: trabajar en alianza o en red con sus contrapartes. No obstante, la mayoría de las organizaciones tienen una trayectoria larga de ayuda. Es decir, han funcionado sin grandes impactos publicitarios pero eso sí, de manera sostenible y cooperativa. El objetivo ha sido contribuir a la reducción de la pobreza en el mundo, asegurar la paz, proteger el medio ambiente y ayudar en el proceso globalización de manera justa y sostenible (Quevedo, 2009, p. 1).

La cooperación se ha enmarcado a partir del 2007 en un nuevo conjunto de directrices legales que rigen las relaciones de la UE con el resto del mundo, incluido América Latina. Estas no son solamente redes o subsistemas de cooperación subregionales, bilaterales, sino globales y de extensa complejidad según las debilidades que para este propósito de integración regional aún enfrenta la región de Suramérica. Estas directrices se reflejan en compromisos que cubren amplios sectores regionales y contribuyen a la búsqueda de una salida política a los conflictos, particularmente, al conflicto armado interno de Colombia (Quevedo, 2009, p. 1).

Estos compromisos tienen su génesis y fundamento en la estrategia de contribución a la paz y a la estabilidad de las naciones. Sin embargo, no hay que perder de vista el gran potencial de desarrollo económico que podría suponer para la región Andina una Colombia en paz (Comisión Europea, 2007, p. 3).

En este sentido, la declaración de Copenhague sobre la Identidad Europea de 1973 es coherente y enuncia que hay un compromiso de los Estados miembros en la defensa de los principios de representación democrática, el Estado de Derecho, la justicia social y el respeto a los Derechos Humanos. Esto es ratificado por el Tratado de Maastricht de 1992, el tratado de Ámsterdam de 1997 y el nacimiento de la Unión Europea (UE), que refuerzan el interés por esa obligación. También lo hacen la Carta de los Derechos Fundamentales de la Unión Europea de 2000, la aprobación en el Consejo Europeo de Niza del 2001, el nuevo Tratado de Lisboa de 2009 que confirma la importancia de los Derechos Humanos, y el tratado por el cual se establece una constitución para Europa de 2004 (Pastrana, 2006, p. 246).

Sin embargo, la política exterior alemana se inserta en la de la UE, en la política de cooperación y desarrollo que tiene como objetivo, en parte, la promoción de alianzas o redes de cooperación que ayuden con capacitación y recursos para combatir la raíz del conflicto armado en Colombia. Aunque esto no siempre es coincidente, por lo menos a corto plazo, parece claro que es bastante difícil considerar a una Alemania independiente de la 
UE en muchos campos, dado que esta nación es parte decisiva de la política de coordinación y aplicación de la UE y también de la Política Exterior y Seguridad Común (PESC).

Además de esto, la política exterior de la UE en relación con terceros países promueve otras medidas de apoyo y denuncia de las situaciones de violación de los DDHH en América Latina. Ellas se ven realizadas por medio de acciones de instituciones de justicia, convivencia y Derechos Humanos, que ha llevado a cabo la Delegación de la UE con Colombia y que han consistido fundamentalmente en ayuda financiera para la paz y la reconstrucción. Asimismo, gran parte de los modelos y estrategias de justicia transicional para lograr la paz han sido esfuerzos en cooperación con organizaciones nacionales e internacionales que representan a las víctimas del conflicto (Avello, 2008, p. 4).

Estas acciones en red o subsistemas de las instituciones de la UE con el continente suramericano (CAN, UNASUR, MERCOSUR) aún acusan debilidad pues sólo han logrado expresión parcial de la región. A pesar de ello, se enfocan hacia varios campos específicos que incluyen los Derechos Humanos, la justicia y la convivencia, los pueblos indígenas y la cooperación al desarrollo de la comunidad y de los Estados miembros, la política de la UE frente a los terceros países con relación a la tortura y otros tratos o penas crueles, inhumanas o degradantes, niños y conflictos armados, defensores de los Derechos Humanos, fomento al derecho internacional humanitario; promoción y protección de los derechos del menor, violencia contra las mujeres y la lucha contra todas las formas de discriminación contra ellas (Pastrana, 2006, p.251).

De igual forma, también se han consolidado en compromisos que se demuestran con los apoyos dados a los gobiernos y entes judiciales en temas puntuales como el acompañamiento a periodistas, sindicalistas, organizaciones y defensores de Derechos Humanos amenazados. Esto relieva el respeto, la igualdad y la democracia como principios fundamentales de la UE (Delegación de la Unión Europea para Colombia, 2008, p. 5).

No obstante, a partir de 2007 las relaciones entre la UE y los países latinoamericanos son regidas por un nuevo marco o instrumento de cooperación al desarrollo, como se ha anunciado, que constituye la nueva base jurídica principal de la cooperación, aunque no la única, siempre bajo el paraguas de la declaración institucional "Consenso Europeo Sobre la Política de Desarrollo de 2005” en donde particularmente los alemanes están destacando entre otros compromisos la contribución a la paz y la convivencia pacífica de Colombia por medio del diálogo y la cooperación.

En otras palabras, la estrategia de la UE con Colombia 2007-2013 deberá entenderse en el marco de la declaración "Consenso Europeo Sobre Desarrollo" adoptado por el Parlamento europeo, el Consejo de Ministros, los Estados miembros y la Comisión de 2005. Aquí el tema central ha sido la erradicación de la pobreza en el contexto del desarrollo sostenible y de los objetivos de desarrollo del milenio. Sin embargo, en ella se subraya también la importancia de mantener una relación de asociación con los países en desarrollo 
y de promover el buen gobierno, los Derechos Humanos y la democracia, con la finalidad de que la globalización sea más equitativa. De este modo, la declaración va a prever un enfoque diferenciado en función del contexto y las necesidades, y propone un marco temático común que incluya la cohesión social, el empleo, el comercio y la integración regional entre las prelaciones de la cooperación comunitaria (Comisión europea, 2007, p. 8).

En resumen, los compromisos de Alemania y Colombia vienen desde hace casi 50 años desarrollando la cooperación y el esfuerzo común para lograr la paz y el desarrollo sostenible. Esto se ha reforzado a partir de 2007 con el nuevo régimen legal que ha establecido la UE para el desarrollo de las naciones, incluyendo América Latina y particularmente Colombia, debido a la larga duración del conflicto armado que conlleva una complejidad específica en donde la desconfianza entre el Estado y la sociedad civil es grande y se necesita la superación de esta situación con la ayuda subregional, bilateral y multilateral. Esta es una meta que se ha planteado la cooperación alemana para el desarrollo junto con otros donantes. De este modo, el trabajo en el terreno tendrá que entrelazarse por medio de alianzas o redes que articulen los actores supranacionales, estatales, regionales, locales, instituciones públicas y privadas de los Estados con una gama más amplia de posibilidades de intervención en la solución de los conflictos, todo con el fin de lograr también el acercamiento del terreno y sus habitantes (Embajada de la República Federal de Alemania, 2007, p. 8).

En Suramérica se ha venido construyendo una variedad de campos de gobernanza que son acordes a una visión regional, los cuales parece que apuntan a mayores niveles de articulación entre los países de la región para enfrentar problemas comunes transfronterizos (Oddone, 2013, p. 261). En este orden de ideas, se piensa que el trabajo avanza hacia sobrepasar la autoridad de los Estados como fue el caso de la UE. Asimismo, se ha considerado que las instancias multilaterales como UNASUR y resulta conveniente para realizar acercamientos a conceptos como regionalismo y gobernanza multinivel, en tanto permiten aproximarse desde una óptica académica a las características del proceso de configuración de Suramérica como una región (Simmons, 2013, p. 27).

En este contexto, también es preocupante la estrecha interdependencia del sistema económico mundial en donde ninguna economía nacional queda libre de las crisis de otros países y regiones (Del Arenal, 2008). Sin embargo, los riesgos aquí aparecen latentes cuando los pilares de la economía de una nación dependen de una economía mundial estable. Es en este sentido, que las crisis financieras y económicas por ejemplo de regiones como África, Asia o América del Sur, terminan impactando a otras naciones. Por tanto, una cooperación al desarrollo orientada hacia la estabilización de las economías de los países contraparte fortalece también la economía de los países donantes (Pastrana \& Aponte, 2006, p. 254).

Sin embargo, la violencia es un fenómeno que también preocupa a la UE porque si esta situación tiende a degradarse afecta a los sistemas económico, político y social, y 
es evidente que la inestabilidad de un país incide notablemente en la prosperidad de los otros, en las relaciones internacionales y en la inserción en el mundo. Así pues, la paz en Colombia se convierte en un objetivo prioritario no solamente para la UE sino para la comunidad internacional.

En otras palabras, el conflicto armado interno colombiano adquiere relevancia con las estrategias de cooperación subregional, bilateral y global de la UE y particularmente de los alemanes, cuando éstas se orientan a contribuir con la solución del mismo, máxime si la ayuda se enmarca en una dimensión de potencia civil y humanitaria que contrasta con la ayuda militar que promueven los EEUU en el marco del funesto Plan Colombia (Quiroga, 2010, pp. 2-3).

Hoy se estila un nuevo concepto de gobernanza en la UE que recorre un camino distinto para indicar un nuevo estilo de gobierno, un gobierno diferente del modelo de control jerárquico y tradicional que se caracteriza por un mayor grado de cooperación y por la interacción entre el Estado y los actores denominados no estatales en el seno de las llamadas redes decisionales mixtas. El nuevo concepto se centra en las funciones desempeñadas por el conjunto de actores públicos y privados que aparecen implicados en los procesos políticos. Este es un método o mecanismo que se aprovecha para afrontar una amplia gama de problemas o conflictos en que los diversos actores generalmente alcanzan acuerdos satisfactorios y de cierta manera obligatorios por medio de las deliberaciones y las negociaciones, pero al mismo tiempo, cooperan en la implementación de dichos acuerdos (Morata, 2004, pp. 23-26).

\section{Principios orientadores de la política exterior alemana frente a la salida negociada del conflicto armado en Colombia}

En la era de la globalización, la política exterior de los alemanes se caracteriza porque Estados, sociedades y espacios económicos, se relacionan y actúan interdependientemente. Sin embargo, el final del conflicto Este-Oeste fue el que brindó esas nuevas expectativas a la política exterior alemana, tanto en Europa como a nivel del mundo (Hintereder, 2013, p. 1).

Los alemanes han asumido la redoblada responsabilidad internacional que se deriva para la nación en los cambios operados en la esfera mundial y de consuno con sus socios de todo el globo, mantienen un activo compromiso en pro de la democracia, los Derechos $\mathrm{Hu}$ manos y el diálogo entre las civilizaciones. Aquí el objetivo prioritario de la política exterior ha sido el mantenimiento de la paz y la seguridad internacionales (Añaños, 2008, p.5).

En otras palabras, los Estados están siendo obligados a recurrir a un mayor bilateralismo y multilateralismo para la solución de los problemas mundiales, debido a que el carácter transfronterizo implica instrumentos como la cooperación internacional para abordarlos. De este modo, el concepto de gobernanza aparece respaldado en diversos 
niveles de coordinación, cooperación y búsqueda de soluciones comunes en la esfera internacional (Pastrana, 2005, p. 282).

No obstante, los principios de la política exterior para cooperar específicamente con Colombia han tenido su base no solamente en el poder ejecutivo sino en las transformaciones políticas del mundo, y se enmarcan más en lo multilateral y bilateral que en lo global; entre estos se encuentran la democracia, la libertad, el Estado de derecho, la gobernanza y el respeto a las libertades fundamentales que están en la base de la construcción de la política exterior alemana y de la política exterior europea, así como la ayuda mutua, la reciprocidad, la solidaridad, la hermandad, la justicia y los Derechos Humanos (Schunemann, 2006, p. 6).

En este sentido, la coexistencia armónica entre pasado y presente conlleva a tener en cuenta todos los intereses en juego, como por ejemplo los derechos de las víctimas en el campo de la verdad y la reparación, los cuales también son de transcendencia fundamental. Sin embargo, resulta imprescindible el respeto a los principios democráticos como garantía del Estado de Derecho (Ambos \& Meyer-Abich, 2009, p. 10).

Ahora bien, los Estados acosados por la fuerza de la globalización le están apostando también a diversos mecanismos que faciliten atender la gobernanza de los problemas globales e interregionales, bilaterales o multilaterales, por medio de la promoción de alianzas o redes de cooperación entre actores públicos y privados (Pastrana, 2005, p. 283).

Sin embargo, para esta empresa se han multiplicado los escenarios pero también se ha comenzado a cooperar con otros actores que incluyen instituciones económicas, científicas y ciudadanas, a diferencia del papel jerárquico y de cierto modo autoritario del pasado. No obstante, aquí se observa el comienzo de una propuesta o de un papel negociador o mediador para enfrentar los grandes problemas de orden social y político de los países desde otra perspectiva, con la conceptualización sobre un nuevo modelo de gobernanza (Pastrana, 2005, p. 284).

Por otro lado, al hablar de los efectos que puedan generar las acciones de cooperación internacional, y de manera particular, la política exterior de los alemanes con respecto a la solución negociada del conflicto armado y la aplicación de la ley de Justicia y Paz, será clave volver sobre la dinámica del mercado mundial, la caída del muro de Berlín y el colapso de la Unión Soviética, que como ya se ha dicho, produjeron transformaciones muy importantes en la concepción y vigencia de los Estados nacionales (Pardo, 2001, p.2).

Igualmente, es necesario mencionar el fortalecimiento de un consenso en torno a la democracia como sistema de gobierno de los Estados. Es decir, la promoción por los actores políticos del mundo de la democracia como sistema político, lo cual lleva a que se multiplique el modelo en gran escala y en diversos países.

En este sentido, la exclusión de la democracia por los autoritarismos trae consecuencias políticas y económicas que se reflejan en la imposibilidad de mantener vigentes relaciones internacionales normales con la comunidad global. 
Debido a estas conexiones que encara la dinámica mundial, el concepto de democracia como modelo de gobierno se ha instalado en el mundo y se convierte en una demanda permanente por mantener la vigencia y su consolidación en las diversas naciones.

En este orden de ideas, las exigencias a la comunidad internacional y la cooperación misma de los Estados son cada vez mayores para ayudar en la construcción de este sistema de gobierno. Es por esto que la comunidad internacional cada vez se ve más legitimada para intervenir incluso por la fuerza y defender la construcción del sistema democrático.

Igualmente, los ciudadanos cada vez se comprometen más con la democracia y buscan respuestas concretas de solución a los fenómenos sociales, al buen gobierno, a la lucha contra la corrupción, el respeto a los Derechos Humanos y a la solución de los problemas de la vida cotidiana. En este sentido, se construye una presión de la comunidad internacional (externa) y una presión (interna) de los ciudadanos de los Estados.

Este fenómeno abre las puertas a la comunidad internacional para la cooperación y la construcción de la democracia, y obliga a una mayor flexibilidad en las normas relacionadas con la no intervención de los Estados en los asuntos internos de los países.

Aquí se abre un debate sobre la vigencia de la no intervención aunque hoy en día casi nadie defiende esa concepción original. Por el contrario, la concepción que fluye es la que intenta promover fórmulas alternativas de intervención aceptables a partir de la revisión del principio de no intervención, el deber de la injerencia humanitaria, el derecho a la no injerencia, la supranacionalidad y la cooperación jurídica, etc. (Pardo, 2001, p. 2-4).

No obstante, las características de la internacionalización tanto del conflicto como del proceso de paz se transforman sustancialmente con la visión de la globalización, pero también con el auge de las redes de cooperación que promueven los distintos países por medio de los tratados bilaterales y multilaterales entre las naciones que hacen parte del mundo en desarrollo (Cardona, 2011, pp. 21-25).

Así pues, el fortalecimiento de valores dominantes como la democracia y los Derechos Humanos en la comunidad internacional, impacta de algún modo los actores del conflicto armado de Colombia cuando se generan mayores exigencias en la condena de prácticas como los incumplimientos del DIH, la tolerancia frente al fenómeno de las drogas ilícitas y las sindicaciones a los actores armados de participar activamente en estos actos delictivos.

De modo que el escenario mundial de la globalización de ciertos fenómenos nacionales implica desafíos para el Estado colombiano, pues muchos de estos hechos afectan su margen de maniobra, tanto con los actores públicos como con los privados, para orientar el proceso de paz. Sin embargo, el carácter eminentemente interméstico de los principales puntos de la agenda de gobierno del presidente Santos conduce a una 
política exterior más vinculada a la agenda doméstica, y en consecuencia a una reducción de los márgenes de maniobra autónomos o meramente nacionales. Así pues, un extenso campo de acción en los grandes temas nacionales lo dinamizan los gobiernos y los actores extranjeros, y muchos temas de la agenda doméstica tienen un margen de acción que depende de acciones de política exterior.

En este orden de ideas, en la gobernabilidad interna de los Estados hay temas en donde la visión de la comunidad internacional choca con las posiciones que no son de consenso o cuyo consenso presenta debilidades, lo cual impacta en el poder negociador del gobierno y de los Estados.

Es por esto que hay que observar la normatividad interna y externa en una vía doble en donde el proceso de paz se surta con estrategias del marco de las relaciones exteriores y lo haga viable desde el punto de vista de los beneficios y la inclusión de costos. Esto para ver a Colombia insertada normalmente en el sistema internacional. Esa tarea depende del enfrentamiento y solución de los problemas internos (Ramírez, 2011, p.79).

No obstante, se observan escenarios de internacionalización positiva y negativa; la diferencia entre uno y otro, parte del hecho evidente de que los países que participan en esfuerzos de paz, los promueven fundamentalmente por motivos egoístas, porque la política exterior de los Estados se diseña para atender intereses nacionales por lo que estos raramente se identifican con los de otros Estados (Tokatlian y Pardo, 1987, pp. 113-154).

Ahora bien, entre los impactos de mayor transcendencia de la cooperación en los procesos de paz pueden relacionarse los siguientes: la búsqueda de la paz y la mitigación de las consecuencias del conflicto armado; la asistencia a las víctimas de la violencia para reivindicar sus derechos ante los tribunales nacionales o internacionales; la promoción de la paz a nivel local y nacional haciendo que los recursos que invierte la UE y Alemania particularmente no se desvíen para el fomento de la guerra; el impulso a los laboratorios de paz fundados con instituciones locales y con la sociedad civil; la promoción del desarrollo para todos los ciudadanos; el combate y la lucha frente a las raíces del conflicto armado; y el Ataque frontal contra la desigualdad social.

Además, hay cambios de visión de las corporaciones comprometidas con la cooperación internacional sobre los papeles que desempeñan en las zonas de conflicto, cambios en la construcción de región, lo que hace ver que hay diversas opciones para construir paz, y en la promoción de alianzas entre la comunidad y el Estado (Oficina Internacional de los Derechos Humanos Acción Colombia, 2009).

En síntesis, el diálogo entre la UE y Colombia fluye propiciando que se cumplan los principios de la democracia y las normas del DDHH y del DIH que han sido resultado de los tratados internacionales y uno de los objetivos fundamentales de la política exterior, y de seguridad común de la UE (Pardo, 2001, pp. 2-4). 


\section{La cooperación alemana en Colombia por medio de los programas más destacados}

Entre los programas de cooperación llevados a cabo por actores públicos y privados relacionados con el conflicto interno colombiano que más se destacan en la última década en Alemania, se encuentran los siguientes:

1. "Programa de construcción de la paz". Es un proyecto combinado de Cooperación técnica (IGZ) y Cooperación financiera (KfW) que se ha ejecutado en estrecha coordinación y colaboración con InWEnt y CIM.

2. "Programa de la Comisión Nacional de Reparación y Reconciliación" (CNRR). Aquí las agencias ejecutoras alemanas han colaborado estrechamente con las regionales y nacionales en el interés del éxito del programa.

3. "Programa CERCAPAZ" (Desarrollo de la Paz por medio de la promoción de la colaboración entre el Estado y la Sociedad Civil). Se ha hecho énfasis en factores que en Colombia debilitan gravemente la operatividad del Estado de Derecho y quebrantan la confianza de los ciudadanos en sus instituciones públicas y privadas. La misión del programa CERCAPAZ alcanza muchos otros fenómenos que inciden en el reconocimiento del Estado y en lo que socaba la confianza de los ciudadanos en sus instituciones como el clientelismo, la corrupción, los enfrentamientos con grupos armados ilegales, la producción y comercialización de narcóticos, así como la implicación de agentes estatales en la dinámica de la violencia que desde hace muchas décadas castiga a la nación, pero también la capacitación de los agentes tanto del Estado como de la Sociedad Civil en la solución pacífica de los conflictos dado que en amplios sectores de la población la violencia se considera un medio eficaz para la solución de conflictos. Es decir, las personas presentan dificultades para manejar mecanismos democráticos y constructivos que sirvan a ese propósito, lo que se evidencia en todos los ámbitos de la vida, incluso en los núcleos familiares donde hay diversas tensiones o enfrentamientos que vienen desde hace varias generaciones (Pastrana, 2011, p. 201).

4. "Programa FortalEsDer". Se lleva a cabo por encargo del Ministerio Federal de Cooperación Económica y Desarrollo (BMZ) y opera en cuatro diferentes áreas: 1. Fortalecimiento y fomento de la eficiencia institucional del poder judicial y de los organismos de control (Defensoría del Pueblo y Procuraduría General de la Nación); 2. Arbitraje extrajudicial de conflictos administrativos; 3. Formación de una política legal, proactiva y de globalización jurídica; y 4. Justicia transicional.

5. "Programa ProFis" Contribuye al entendimiento del conflicto armado entre el ejército colombiano, los grupos paramilitares y la guerrilla que existe hace varias décadas. En este lapso de tiempo se han cometido graves violaciones a los 
Derechos Humanos. Su tratamiento jurídico es uno de los mayores retos que enfrenta Colombia. (Embajada de la República Federal de Alemania, 2011, pp.6-16).

6. "Programa de restitución de tierras" (ley 1448 de 2011), inserto en el apoyo y la ayuda del sistema de cooperación internacional. Aquí la Oficina Asesora de Planeación, con el sostén de la subdirección general, mantiene una permanente comunicación con las instituciones interesadas, y gestiona y formula proyectos para acceder a las fuentes de financiación de conformidad con las metodologías que exige cada cooperante internacional. En este sentido, con la finalidad de identificar las prioridades de la cooperación, la coordinación del Ministerio de Agricultura y Desarrollo Rural (MADR) y la agencia de cooperación internacional de Colombia dan apertura a la mesa de tierras para la cooperación internacional. Particularmente, en relación con la UE se trabajó en los términos de referencia de una primera asistencia técnica cuyo propósito estuvo orientado a la instrumentalización de la política de restitución de tierras. También se observan otras naciones que han expresado su compromiso con el programa, como la cooperación francesa que igualmente se inserta en el marco de las líneas estratégicas del cooperante europeo. En este orden de ideas confluyen otros compromisos de cooperación con subsistemas de España y Suecia (Ministerio de Agricultura y Desarrollo Rural, 2012, p. 15).

Todos los programas que se vienen desarrollando están de acuerdo con la Constitución de 1991 que establece que Colombia es un Estado Social de Derecho caracterizado por el mantenimiento de la paz (jurídica) y la protección de la población contra actos arbitrarios de las autoridades. En este marco, se promueve entonces el fortalecimiento del Estado de Derecho que vigoriza el control del poder ejecutivo por medio de organismos externos y la justicia, dado que todavía existe una enorme distancia o brecha entre los principios constitucionales y la realidad social.

Por otro lado, Además de la cooperación bilateral y subregional, existe la cooperación multilateral para el desarrollo como consecuencia de la interdependencia de las naciones. Según esto, el Gobierno Alemán apoya a organizaciones que operan a nivel mundial como por ejemplo el Comité Internacional de la Cruz Roja. De modo que alrededor de un tercio del presupuesto del BMZ llega a los países en desarrollo a través de instituciones multilaterales, tales como el Banco Mundial, bancos regionales de desarrollo, Fondos y programas de las Naciones Unidas, entre otros (Ministerio de Asuntos Exteriores y de Cooperación española, 2012, p. 1).

\section{Las experiencias alemanas frente a la justicia transicional}

Alemania tuvo dos experiencias de transición que han impactado todos los referentes de justicia transicional. La primera fue la transición al finalizar la Segunda Guerra 
Mundial, en 1945, cuando el país buscó dejar atrás todas las violaciones contra los Derechos Humanos durante la dictadura del Nacional Socialismo. La segunda surgió tras la caída del Muro de Berlín al pretender el logro de la unificación de Alemania superando la dictadura comunista. Estas experiencias aportaron significativamente al desarrollo de la justicia transicional, y le sirvieron no sólo al país para reconstruir la nación, sino a todos los países que promueven la utilización de modelos de transición con pretensiones de construir paz y/o consolidar la democracia.

La transición alemana después de la dictadura Nazi fue orientada por la comunidad internacional representada en los países vencedores de la Segunda Guerra Mundial. Entonces, los países aliados condujeron los denominados Juicios de Nuremberg, que pretendían determinar la responsabilidad criminal del Reich a nivel internacional; para esto se buscó judicializar individualmente a los máximos responsables que dirigieron las violaciones sistemáticas y constantes de los Derechos Humanos. En este sentido, la justicia transicional comienza a ser entendida como extraordinaria e internacional en el periodo de la posguerra de 1945 (Teittel, 2003, p. 69).

De igual forma, los aliados dirigieron la transición mediante diferentes medidas penales, cuasipenales y extrapenales, que se encargaron del pasado nacional socialista y de la construcción en Alemania de un orden democrático regido por los principios del Estado de Derecho. Asimismo, hubo numerosas acciones de reparación, indemnización y de rehabilitación (Ambos \& Meyer-Abich, 2009, p. 435). Ahora bien, con el objetivo de hacer a un lado la estructura nacional socialista se disuelve instituciones, se deciden despidos y se ejecutan medidas reeducativas. Así mismo, para 1950 con el propósito de generar una mentalidad del punto final, algunos victimarios u ofensores contra la humanidad fueron amnistiados, integrados y protegidos contra futuras medidas de persecución penal; esto tenía como objetivo reconciliar a la nación (Ambos \& Meyer-Abich, 2009, p. 436).

Ahora bien, la transición hacia la unificación alemana tras la dictadura comunista se dio fundamentalmente por medios jurídico-penales; aquí los procesos fueron llevados adelante en principio por las autoridades de persecución penal y tribunales ordinarios de la República Democrática alemana en 1989, por la presión de la sociedad civil y la protesta pública, y después, con la unificación el 3 de octubre de 1990, fueron continuados por las autoridades de la República Federal Alemana. No obstante, en el marco de la aplicación de los códigos penales de la RDA y luego de la RFA, fueron también consideradas figuras jurídicas y principios del derecho internacional público. En el ámbito extrapenal se sancionaron numerosas leyes de rehabilitación, de reparación y de resarcimiento. Además, se crearon dos comisiones que apoyarían el proceso de transición (Ambos \& Meyer-Abich, 2009, pp. 437-438).

Igualmente, tras la unificación de las Alemanias las normas aplicadas con vistas a la invalidación de investigaciones fueron la Ley de los archivos de la Stasi de 1991 y 
los artículos correspondientes del tratado de unificación de 1990. Particularmente y en relación con el tema de las restituciones de la propiedad, el objetivo fue compensar a las víctimas por lo que el régimen anterior les había privado. Estas restituciones, en principio, debían responder a diversos interrogantes relacionados con los tipos de injusticias llamadas a reparar dado que el debate se centra en que se puede devolver una propiedad pero no los años pasados en prisión.

Otro de los temas clave que se reporta es el enorme interés de la relación entre justicia transicional, verdad e historia, porque el discurso de la justicia transicional implica volver a interrogar el pasado como paso previo o un modo de avanzar hacia el futuro. Esto quiere decir que existe una noción implícita de una historia que progresa. Sin embargo, esta noción está cuestionada desde la perspectiva de la historiografía y el auto-entendimiento humano.

Aquí lo paradójico es que el objetivo es deshacer la historia, re-concebir el significado social de conflictos pasados, en particular de las derrotas, en un intento por reconstruir sus efectos presentes y futuros. En este sentido, el primer caso de justicia transicional o justicia retroactiva, como es denominada por diversos autores, se da en Alemania a partir de 1989. Ello ocurre porque Alemania es el país con una importante experiencia en la forma de tratar crímenes del pasado, pero también porque la RDA dejó de existir después de la unificación (CEPC, 2006, p. 3).

No obstante, a partir de la caída del muro de Berlín la Historia dio cuenta de una serie de cambios políticos y sociales que desencadenaron en la unificación de la nación alemana, lo que produjo como resultado el fin de la Guerra Fría. Esta nación unificada empezó a juzgar a funcionarios y militares por las personas que intentaron escapar durante la existencia del muro y resultaron muertas. Por tanto, desde 1991 hasta 2004, cuando se dicta la última sentencia en este tipo de procesos, se tuvo noticias de 240 procesos penales contra soldados de frontera, superiores militares y dirigentes políticos. También, sucesivamente, empezaron a caer los regímenes de la cortina de hierro soviética, entre tanto, a lo largo de los años 90, se crearon diferentes tribunales internacionales ad-hoc, como los de Yugoslavia y Ruanda, cuya génesis sólo fue posible por la unanimidad en el Consejo de Seguridad de las Naciones Unidas, que toma la decisión de crearlos según el capítulo VII de la Carta de Naciones Unidas (Coalition for the International Criminal Court, 2005, pp. 1-3).

Estas experiencias han demostrado que es posible superar y enfrentar graves y sistemáticas violaciones contra los Derechos Humanos desde que exista voluntad política y social para edificar una paz duradera. A su vez, envían el mensaje a los Estados del mundo que permanecen inmersos en conflictos armados y a los regímenes autoritarios de que desde los marcos políticos y normativos de la justicia transicional es posible proyectar una paz sostenible que contribuya directamente al desarrollo social y económico de cualquiera de las naciones. 
Finalmente, se puede inferir que tales experiencias han cimentado importantes referentes tanto para la construcción teórica de los modelos de justicia transicional como para la aplicación empírica de los presupuestos conceptuales. Las experiencias alemanas han dejado huella para diseñar e implementar estrategias exitosas que han marcado la historia del mundo en el contexto de transición hacia la paz y la consolidación democrática.

\section{La percepción alemana frente a la adopción e implementación de la ley de justicia y paz en Colombia}

En Colombia, durante el mandato del Expresidente Álvaro Uribe, se creó la Ley 975 de 2005, más conocida como la Ley de Justicia y Paz; ésta tuvo como principal propósito establecer condiciones para la reincorporación de miembros de grupos armados organizados al margen de la ley que contribuyan de manera efectiva a la consecución de la paz nacional (según norma publicada en Diario Oficial No. 45.980 de 25 de julio de 2005). También se afirmó que la ley es la primera que incorpora estrategias jurídicas para la desmovilización de miembros de grupos armados organizados al margen de la ley, acompañadas de medidas de reparación para las víctimas (Cuervo \& Becerra, 2007, p. 23-25).

La ley fue aprobada por el Congreso de la República el 21 de junio del 2005 pasando por intensos y espinosos debates políticos; el marco jurídico de Justicia y Paz fue objeto de profundas críticas de distintos actores políticos. Es así como la Oficina del Alto Comisionado de las Naciones Unidas para los Derechos Humanos en Colombia expresó que la ley 975 de 2005 aprobada por el Congreso

\footnotetext{
No logra reunir los elementos esenciales aconsejables para establecer una justicia transicional que, en aras de ser un instrumento de paz sostenible, prevea incentivos y ofrezca beneficios para que los grupos ilegales se desmovilicen y cesen sus hostilidades, a la vez que garantice adecuadamente los derechos de las víctimas a la verdad, a la justicia y a la reparación. (Organización de las Naciones Unidas, 2005, p. 1.)
}

Del mismo modo, actores no gubernamentales como Human Rights Watch (2005), entre otros, han denunciado ante la comunidad internacional "que la ley 975 de 2005 no incluye mecanismos eficaces para lograr una genuina desmovilización y desmantelamiento de grupos armados. A su vez, la ley no satisface estándares internacionales sobre verdad, justicia y reparación para las víctimas" (2005, p. 1). Así pues, desde diversos sectores sociales y políticos se adujo que la ley no cumplió con las obligaciones contenidas en el principio de verdad y reparación (De Greiff, 2008), principalmente porque no garantiza el derecho a las víctimas a la reparación integral y la verdad (De Greiff, 2005).

A pesar de las anteriores críticas, entre muchas otras, el gobierno impulsó la adopción y aplicación de la Ley de Justicia y Paz. No obstante, la Corte Constitucional en sentencia 
C-370 del 2006 manifiesta la constitucionalidad en general de la ley pero declara inexequibles algunas disposiciones y modifica otras en torno al marco jurídico para reparar a las víctimas (Valdivieso, 2012). La Corte argumentó que el Estado tiene el deber de buscar la paz, y la paz tiene esencia axiológica y constitucional y constituye de suyo un derecho fundamental, y como tal, es un fin legítimo cuya persecución admite restricciones a algunos derechos siempre y cuando, dichas restricciones sean proporcionadas.

En cualquier caso, los derechos de las víctimas no pueden desaparecer. Es por ello que todo proceso de paz debe sujetarse al cumplimiento de los parámetros internacionales en materia de DDHH y DIH (López y Vargas, 2009). Además, comprendiendo el complejo contexto colombiano, se considera que la verdad, la justicia y la reparación son necesarias en su integralidad para abordar el difícil camino de paz nacional (Díaz, 2008, p. 12).

Ahora bien, para el gobierno del expresidente Uribe la Ley de Justicia y Paz (en adelante LJP) fue un instrumento jurídico vital para uno de sus objetivos gubernamentales: el proceso de desmovilización y reinserción a la vida civil de grupos armados al margen de la ley, que por disposiciones políticas presidenciales, fue orientado principalmente a priorizar la entrega de beneficios a grupos de autodefensas y paramilitares del país. Así, constituye una preocupación adicional y es que todos los aspectos y los de gran trascendencia para el país se manejen a discreción absoluta del presidente y no por principios orientadores constitucionales o el deber ser (Orozco, 2009, pp. 10-15).

Por esta vía, el Gobierno emprendió una inmensa gestión diplomática con la UE para la consecución de apoyo a la implementación de la LJP., lo cual para la Comunidad Europea es aceptable y plausible cualquier intento por adelantar pasos en procura de construir la paz, dado que esto estaría en concordancia con los principios democráticos y pacíficos que orientan el diseño de políticas en el viejo continente. En este sentido, el Consejo de Asuntos Generales y Relaciones Exteriores adoptó la declaración No. 2678 del día 3 de octubre de 2005, en la cual expresa su posición tradicional de apoyo al gobierno de Colombia a través de su política de cooperación para el fortalecimiento institucional y ayuda humanitaria, no sin enfatizar en la necesidad de búsqueda de una solución negociada del conflicto armado y en el cumplimiento de las recomendaciones internacionales en materia de DDHH (Pastrana, 2006, p. 4).

Lo anterior fue cuestionado duramente, pues se confrontaba con una avalancha de críticas nacionales e internacionales frente a la legitimidad de la ley. En este sentido, sectores de la sociedad civil y organizaciones no gubernamentales de protección a víctimas argumentaron que no se podía pedir apoyo internacional para una ley que fue aprobada por un Congreso integrado por más de sesenta miembros supeditados judicialmente por vínculos con paramilitares (Sikkink, 2010, p. 459).

Así pues, la UE reconoce la LJP a pesar de su carácter controversial y acepta que puede ser un paso importante en el proceso de construcción de un marco jurídico para 
la solución del conflicto colombiano. En este sentido, se percibe como la primera ley que intenta incorporar principios de verdad, justicia y reparación, estableciendo un mínimo de condenas y judicialización a los desmovilizados. Ahora bien, desde una perspectiva comparada se diferencia de los marcos jurídicos que privilegian las amnistías e indultos, tan criticados por la comunidad internacional (Pastrana, 2007a, p. 3).

En esta línea el apoyo de la UE, por medio de las directrices de la Estrategia Europea de Seguridad (ESE), se da por el convencimiento de la intensificación de los procesos de globalización, por tanto, la distancia geográfica está perdiendo importancia para la política de seguridad puesto que, los conflictos y problemas en regiones lejanas, pueden tener efectos negativos, directos o indirectos, sobre la UE y su seguridad. Por tal razón, la ESE identifica a los conflictos armados locales y regionales irresolutos como grandes amenazas para la estabilidad del sistema internacional (Pastrana, 2007b, p. 4). De esto se puede inferir que para la UE siempre ha sido importante impulsar políticas orientadas a la búsqueda de soluciones pacíficas y negociadas a los conflictos en general. El marco de la cooperación binacional tiene interés directo en apoyar la solución política del conflicto armado en Colombia, considerando que dicho problema impacta diferentes ámbitos sociales que trascienden el territorio nacional.

Por su parte, Alemania denota un especial interés en promover una negociación del Conflicto armado en Colombia, fundamentalmente, impulsando el apoyo al proceso de Justicia y Paz por medio de la implementación de diversos programas oficiales que agrupan actores estatales y no estatales con el propósito de coadyuvar a consolidar la paz. Lo anterior se denota en cuanto a los acuerdos oficiales concertados entre ambas naciones, los cuales se centran en dos áreas específicamente delimitadas: "Prevención de conflictos, desarrollo para la paz sostenible y fortalecimiento del Estado de derecho”, y "Política Ambiental, Protección y Uso Sostenible de Recursos Naturales".

A su vez, se puede interpretar que Alemania percibe la adopción e implementación de la LJP como un tema complejo y de gran importancia para el sistema internacional y se ocupa de diseñar programas de enorme trascendencia para la correcta aplicación de ésta. Es así como surge el Proyecto ProFis de la Cooperación Técnica Alemana, que por encargo del Ministerio Federal de Relaciones Exteriores de Alemania constituye uno de los pilares fundamentales y más relevantes en materia de apoyo al proceso de paz en Colombia en el contexto de la aplicación de la LJP. Este Programa se esboza de manera detallada en el siguiente acápite, describiendo los principales logros y avances en

\footnotetext{
${ }^{1}$ Véase para su ampliación página oficial Cancillería - Ministerio de Relaciones Exteriores. Colombia-Alemania. Disponible en: http://www.cancilleria.gov.co/international/regions/europe/union/ member/germany\#sthash.Cyyfbkwq.dpuf
} 
materia de asesoría sobre los modelos de justicia transicional adoptados por Colombia principalmente en la aplicación de la LJP.

En ese contexto, se puede interpretar que Alemania percibe la LJP como un paso importante para los procesos de transición hacia situaciones de paz. Como se vio en el año 2009 en el que por encargo del Ministerio de Relaciones Exteriores de Alemania, representado por la embajada en Bogotá y con la coordinación del Proyecto ProFis, se organizó el Simposio Internacional "Justicia Transicional en Colombia: 4 años de Ley de Justicia y Paz" en el cual el Embajador alemán Jürgen Christian Mertens expresó:

Quisiera dejar en claro que mi gobierno admira los esfuerzos de las instituciones y de la sociedad colombiana por superar el conflicto y, en particular, el paramilitarismo. La Ley de Justicia y Paz constituye un paso importante en este empeño por alcanzar la paz. Estamos convencidos de que se trata de un ejemplo de justicia transicional que podría servir de inspiración para procesos similares en otras partes del mundo. Nunca antes se ha intentado conciliar de manera integral la justicia con la reconciliación, la reparación de las víctimas y la búsqueda de la verdad. Por ello pensamos que, a pesar de los problemas que subsisten y de la controversia que este enfoque ha generado y sigue generando, el proceso de desmovilización la implementación de la Ley de Justicia y Paz merecen el apoyo de la comunidad

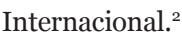

Dado lo anterior, Alemania no sólo demuestra que percibe la implementación de la LJP como un referente importante para los modelos de justicia transicional, sino que también exhortan y promueven a la comunidad internacional que apoye ampliamente tan complejo proceso de pacificación de la nación, pues lo ve como un avance notorio que podría aprovecharse como modelo en otros países.

En este sentido, para Alemania ha sido importante identificar los desafíos que ha encontrado todo el proceso de ejecución de la LJP, como construir la verdad en medio de la violencia, judicializar los victimarios y encontrar los factores que han incidido, las razones de numerosas masacres. En este contexto, desde el fomento de la Cooperación Internacional Alemana, se procura abordarlos de manera directa, incluyendo apoyo en logística y tecnología además de la asesoría que se presta a través del proyecto ProFis.

Así por ejemplo, Alemania, en el marco de sus programas de cooperación, reconociendo las estructuras de gobernanza, ha articulado actores estatales y no estatales para aportar tanto a la ejecución de la LJP como al desarrollo de los diferentes subsistemas que integran el bienestar general de la sociedad colombiana. Es por esto que el anterior

2 Véase para su ampliación Página oficial de la embajada Alemana en Bogotá. 
Embajador del gobierno alemán en la república de Colombia, el Dr. Michael Glotzbach, al finalizar su periodo expresó:

Desde una primera mirada se puede apreciar que la cooperación alemana para el desarrollo cubre muchos ámbitos. Todas las organizaciones, aunque con una visión distinta, tienen algo en común: trabajan en alianza con sus contrapartes colombianas. Esta es una característica propia del compromiso alemán que procura conseguir logros sostenibles a través de la cooperación. (Embajada de la República Federal de Alemania, 2007, p. 5).

Esto demuestra que Alemania concibe y comprende la complejidad del proceso de la LJP en Colombia, para lo cual ha involucrado el trabajo mancomunado de diferentes actores como la GIZ, el KfW, InWent, DAAD y CIM, así como las fundaciones alemanas y las ONG, entre otros, con el objetivo fundamental de abordar las complejidades del contexto.

No obstante, la posición de Alemania frente a la adopción de la LJP ha sido de aprobación general, y frente a su aplicación ha mostrado un activismo en aras a cooperar para abordar las necesidades y problemas que obstaculizan la eficacia de la norma. Así pues, ha mostrado una disposición total de colaboración a las dificultades que se presentan en el proceso de construcción de paz. En suma, Alemania concibe la LJP como un paso relevante hacia la consolidación democrática por medio de la paz sostenible, y por tal razón se ha preocupado por diseñar y promover todo un arsenal de programas de cooperación, pretendiendo fortalecer el proceso de aplicación de la LJP. Se percibe el proceso colombiano desde su experiencia como un modelo contemporáneo de justicia transicional que aporta una gran enseñanza al resto del mundo.

En síntesis, hay una percepción positiva de la UE sobre la solución negociada del conflicto armando y el apoyo a la LJP, lo cual conlleva a que los marcos de cooperación binacional y multilateral cada vez sean más legítimos para enfrentar las diversas problemáticas que transcienden las fronteras nacionales.

En este sentido, en los alemanes despierta un interés especial el participar de una eventual negociación del conflicto armado que facilite el impulso de acciones orientadas a la solución negociada de los problemas y que contribuya al desarrollo de programas que comprometan y empoderen a los actores estatales y no estales en el perfeccionamiento de estrategias de negociación pacífica.

Entonces se podría decir que la UE y los alemanes perciben la LJP como un problema complejo y de preocupación prioritaria para el sistema internacional; pero también se presta especial interés sobre el diseño de programas que orienten una correcta aplicación de la ley de Justicia y Paz.

Los alemanes también expresan admiración a los esfuerzos de las instituciones y de la sociedad por superar las tensiones políticas y el conflicto armando. Además, la LJP 
la perciben como un gran paso en este empeño de alcanzar encuentros en torno a la solución pacífica del conflicto. Aquí recrean varios ejemplos de justicia transicional, pero particularmente el proceso de Colombia dicen podría ser de cierta inspiración para procesos similares en otras partes del mundo dadas sus características y particularidades.

En otras palabras, la nación alemana no solamente entiende el fenómeno de conflicto interno sino que expresa su posición y la demuestra cuando coopera en el impulso de la LJP como un referente importante para los modelos de justicia transicional y cuando exhorta a la comunidad internacional a promover el apoyo a tan complejo proceso de pacificación de la nación colombiana.

\section{El desarrollo del programa de cooperación ProFis/GIZ y sus principales resultados}

El Programa ProFis (compromiso, justicia transicional y resultados palpables) es administrado por la GIZ (Deutsche Gesellschaftfür Internationale Zusammenarbeit) y financiado por el Ministerio de Relaciones Exteriores de la República Federal de Alemania. Este programa ha apoyado desde 2008 a instituciones judiciales para la efectiva aplicación de la LJP. Asimismo, tiene como objetivos contribuir a la unificación de criterios para la aplicación de la LJP y de todas aquellas disposiciones que le son complementarias, incluyendo a la doctrina y a la jurisprudencia.

En el cumplimiento de este cometido ha realizado un acompañamiento jurídico permanente a la Unidad Nacional de Fiscalías para la justicia y la Paz, a los Magistrados de conocimiento y de control de garantías con competencia en el proceso de Justicia y Paz, y a los Magistrados titulares y auxiliares de la sala penal de la Corte Suprema de Justicia (Forer, 2011, pp. 7-8).

ProFis se desarrolla en Colombia a partir de la entrada en vigencia del marco legal para la investigación de los crímenes cometidos aproximadamente por 55.00o hombres desmovilizados. El programa dispuso de un equipo de trabajo compuesto por expertos nacionales e internacionales en las áreas de justicia, policía, política e investigación. Por medio este ejemplar proceso de justicia transicional el país buscó encontrar el equilibrio entre la justicia y la paz para lograr la reconciliación entre víctimas y victimarios y así superar el pasado violento que lo ha caracterizado.

La Ley 975 de 2005, ha conllevado tensiones a las que se enfrentaron las autoridades colombianas en el marco del proceso Justicia y Paz: unos 4.300 de 55.00o combatientes desmovilizados se encontraron dentro del proceso establecido por la ley, deseosos de declarar o que ya habían confesado sus crímenes, más de 52.00o delitos habían sido revelados, y más de 300.000 víctimas o familiares de víctimas habían sido registradas durante el proceso, porque la LJP contempló una persecución penal alternativa para los ex integrantes de grupos armados ilegales siempre y cuando éstos confesaran sus 
crímenes, participaran activamente en la aclaración de los mismos, devolvieran los bienes obtenidos de forma irregular y efectuaran un pago compensatorio a favor de las víctimas. A cambio de cumplir con estos requisitos se les concedió a los culpables una pena de privación de libertad relativamente baja, no mayor a ocho años, que ha soportado duras críticas (Uprimny, 2005, pp. 62-63).

En este sentido, el equipo coordinado por Andreas Forer apoyó la unidad especial de Justicia y Paz de la Fiscalía General de la Nación en la optimización de los procesos operativos y legales, la descentralización de las investigaciones mediante salas móviles de comparecencia y la optimización de los recursos disponibles, dado que el compromiso de la República Federal de Alemania para con el proceso colombiano de justicia transicional abarcó tanto la cantidad de asesorías ofrecidas como la variedad de temas abordados por el programa.

Además se encargó de ofrecer y desarrollar eventos para la capacitación de fiscales, investigadores judiciales y funcionarios del sistema jurídico. Es decir, no se trató únicamente de instruir en la aplicación de la ley, sino de ir mucho más allá en la comprensión del fenómeno o de situaciones problemáticas que se presentaron (Forer, 2011, pp. 10-12).

También se persiguen otros objetivos como el desarrollo organizacional de la Fiscalía, la cooperación eficiente de las distintas entidades implicadas en el proceso y el establecimiento de responsabilidades, así mismo, se incita al compromiso de impulsar seminarios y congresos para el público no especializado sobre estos importantes temas. Las actividades que se promueven desde ProFis tienen como finalidad la sensibilización de los asistentes para las particularidades del proceso de paz y de modo tal que se pueda entrar en una cobertura mediática más apropiada que sirva para fortalecer los derechos de los sectores vulnerables como las poblaciones indígenas y afro-descendientes que han sido fuertemente golpeadas por el conflicto armado interno (Forer, 2011, pp. 12-13).

En definitiva, el programa se destaca por los resultados logrados en este proceso de acompañamiento a la Fiscalía General de la Nación, las redes involucradas y las instituciones que aparecen hoy vinculadas con el desarrollo de la LJP. Entre los resultados de mayor impacto se encuentran: el acompañamiento jurídico permanente a la Unidad Nacional de Fiscalías para la Justicia y la Paz; el acompañamiento a los magistrados de conocimiento y de control de garantías con competencia en los procesos de Justicia y Paz; el acompañamiento a los Magistrados titulares y auxiliares de la Sala Penal de la Corte Suprema de Justicia; los eventos para la capacitación de fiscales, investigadores judiciales y funcionarios del sistema jurídico; los cursos de capacitación orientados al manejo de los delitos sexuales; la elaboración de las directrices para el tratamiento diferencial de las minorías étnicas en el conflicto; el desarrollo organizacional de la Fiscalía, la cooperación eficiente de las distintas entidades implicadas en el proceso y el establecimiento de responsabilidades; el compromiso de impulsar seminarios y 
congresos para el público no especializado en temas de conflicto interno; la promoción y apoyo para los trabajos de identificación de restos mortales de víctimas; la exhumación e identificación de restos por medio del ADN; la definición de estándares para el archivo, organización y conservación de los expedientes de importancia histórica; y la promoción de cerca de 40 publicaciones y conceptos jurídicos sobre temas relacionados con el proceso especial de Justicia y Paz en los que se ha intentado por medio del derecho comparado la adecuación al derecho doméstico de los estándares internacionales en materia de DDHH y DIH., lo cual ya hace parte de la cultura que se construye para enfrentar los temas de la sociedad de posconflicto.

\section{Perspectivas alemanas sobre la cooperación binacional en el marco de un posible acuerdo de paz con la FARC}

En un primer contexto, la UE ha tenido como política principal apoyar las iniciativas de paz en Colombia desde la instauración de la estrategia de "Laboratorios de Paz" creada en el 2002. Estos "laboratorios" han estado orientados al fortalecimiento institucional con el propósito de fomentar zonas de paz, convivencia, desarrollo económico y reconciliación (Comisión Europea, 2007-2013). En este sentido, hasta la fecha la UE denota una gran apuesta política sobre un eventual pacto de paz. Así pues, la UE tendrá una importante percepción positiva sobre un probable acuerdo de finalización del conflicto armado con las FARC. Por su parte, Alemania como parte de la Comunidad Europea tendría el imperativo de diseñar una política en concordancia con las directrices generales que identifican a los países miembros del Bloque de Integración.

Alemania, según su estrategia de política de cooperación internacional desarrollada en la última década en Colombia denota un interés de continuar apoyando desde diferentes ámbitos el proceso de paz. No obstante, hay preocupaciones evidentes. Alemania podría identificar sus inquietudes por ejemplo con las suscitadas por Soledad Granada, Consultora del Instituto GIGA de Estudios Globales de Hamburgo, especialista en conflictos y memoria, cuando argumenta que "es inquietante que la paz en Colombia no ha sido concebida como una política de Estado sino como un instrumento político del gobierno de turno" (Ospina, 2013, p. 1). Por tal razón, y de acuerdo con la consultora del GIGA, se convierte un obstáculo para la transición hacia la paz que ésta sea buscada o promovida por políticas gubernamentales y no estatales. Esto afectaría directamente la continuidad del proceso de paz y además podría impactar el respaldo y la cooperación de Alemania en Colombia.

A pesar de la anterior preocupación, Andreas Forer Coordinador del Proyecto ProFis en Colombia, encuentra plausible que posterior al apoyo ofrecido por Alemania, la Fiscalía haya elevado su capacidad de esclarecimiento sobre la verdad de grupos ilegales (Ospina, 2013). Esto simboliza un avance en la construcción de paz y genera confianza hacía el país alemán para que continúe con su política de fortalecer las 
instituciones en Colombia con el principal propósito de crear condiciones propicias para un potencial pacto de paz.

Ahora bien, Según Forer, Berlín respalda la nueva ley denominada "Marcojurídico para la Paz", la cual ofrecería el respaldo constitucional positivo para un arreglo con las FARC y sería un buen aporte a la recuperación de la memoria histórica (Ospina, 2013). Por tal razón, la perspectiva del posible acuerdo de finalización del conflicto armado con las FARC es positiva y sobre todo propositiva hacía la materialización de un consenso que ponga fin a la violación sistemática contra los DDHH, lo que sería tal vez abordar el camino hacia la construcción de una verdad histórica y la reconciliación nacional que sostengan el andamiaje social de la paz. De igual forma, es relevante interpretar la visita del presidente de Alemania a Colombia a mediados del 2013 en medio de las negociaciones en la Habana como un espaldarazo a una posible solución política del conflicto armado. Es así como Joachim Gauck, Presidente alemán, afirmo que "está dispuesto a brindar todo tipo de colaboración que se pueda requerir de Alemania para el éxito del proceso de paz” (DW.DE., 2013, p. 1)

En este sentido, el Presidente alemán establece que "es importante apoyar al presidente Santos en su política activa en favor de los derechos humanos" (p. 1) como paso fundamental para abordar el camino hacia la reconciliación. También subrayó la relevancia de los logros que se han alcanzado en las negociaciones entre las partes en Cuba. Culminó su intervención afirmando que "mira con respeto el proceso de paz entre el gobierno colombiano y la guerrilla de las FARC, y destacó el esfuerzo que se hace para tratar de terminar con un conflicto armado de casi cinco décadas" (DW.DE., 2013, p. 1).

A manera de síntesis, se percibe que Alemania tiene especial interés en la solución negociada del conflicto armado en Colombia. Para ellos significa un gran paso en la construcción de modelos de justicia transicional, lo cual tendría repercusiones mundiales en el marco de la globalización, pues sería una de las experiencias que servirán como el referente más importante de los últimos años. Entonces, el posible acuerdo de finalización del conflicto con las FARC repercutiría sistémicamente en desarrollo económico y social de Colombia, teniendo como gran efecto el incremento de acuerdos de cooperación entre ambas naciones en diferentes ámbitos, fundamentalmente en los intercambios comerciales.

Ahora bien, si se ha concebido que la paz es condición necesaria para el desarrollo social, es adecuado que Alemania, además de seguir apoyando con los programas anteriormente mencionados que actualmente financia en Colombia, tenga interés en abordar los problemas complejos y estructurales que generan el conflicto armado en Colombia, tales como la pobreza, la desigualdad, la exclusión social y política. Lo anterior se hace necesario, ya que si no se trabaja por la solución dichos problemas estructurales el apoyo alemán se diluye en trabajar por problemas importantes pero no estructurales, sin corregir entonces las causas fundamentales del conflicto armado. 
Si bien es cierto que la justicia transicional proporciona los insumos necesarios para abordar el camino hacia la paz, ésta también potencia los presupuestos para promover la posibilidad de pensar y re-estructurar este país lleno problemas. Por esto es necesario el diseño de programas de cooperación holísticos e integrales que impacten en la sociedad colombiana. En este sentido, se debe procurar complementar el acompañamiento que se realiza a la institucionalidad colombiana con estrategias para la sociedad, puesto que es ésta la que debe desaprender las acciones bélicas y hostiles, la que debe sentirse incluida sobre los beneficios de un Estado Social de Derecho, para así trabajar por construir el difícil camino de la reconciliación nacional.

En suma, las estrategias de educación, de promoción de salud y de inversión social se convierten en aspectos trascendentales para la construcción de la paz sostenible. Así, el diseño de modelos de gestión en diferentes ámbitos podrían socavar las causas estructurales del conflicto armado emprendiendo el verdadero proyecto de reconciliación y de edificar el andamiaje que permita la consolidación de una paz duradera.

\section{El rol de Alemania y la importancia de la cooperación para construir un camino que consolide la paz.}

Un punto importante es la decisión de la UE y de la nación alemana de fomentar la paz, el desarrollo y la democracia por fuera de sus fronteras. Esto está relacionado con su concepción acerca de la seguridad y con el rol que juega en el sistema internacional. Por ello, en vez de priorizar la defensa de sus propios intereses de acuerdo con la visión clásica de la seguridad, alternativamente comprenden que potenciar la gobernabilidad mundial genera favorabilidad a sus propios intereses (Pastrana, 2007b, p. 3).

Sin embargo, hay diferencias entre lo que está escrito y la realidad que se presenta en Colombia, porque a pesar de que la UE se erige como un promotor global de paz, las dinámicas domésticas y de conflicto obstaculizaron la cooperación y la ayuda humanitaria.

Esto lleva a acentuar los aspectos técnicos de la asistencia y a desconocer de cierta forma los aspectos políticos y de largo plazo de la cooperación de la UE. Por tanto, en el análisis de los impactos es clave establecer una lectura de la cuestión mucho más relacional (Tarnaala, 2009, pp. 1-2).

No obstante, los Estados de la UE que brindaron cooperación en los procesos de construcción de paz en la última fase se han transformado en contrapartes silenciosas y discretas en los esfuerzos locales por la paz y la reconciliación social, el empoderamiento político de la denominada sociedad civil, y el fortalecimiento del sistema judicial. Esto no debe entenderse como una merma en el protagonismo, ni en la ausencia de interés en las problemáticas colombianas.

Aquí los virajes en la cooperación se encaminan a entender cómo la promoción de la paz y el desarrollo por parte de actores externos pueden incidir en asuntos locales y 
regionales y hasta abrir espacios clave para grupos previamente excluidos de las acciones por la democracia (Tarnaala, 2009, pp. 3-4).

La búsqueda de la paz en Colombia ha sido considerada como un proyecto a largo plazo que se guía con una mirada de postconflicto democrática. Esto incluye las causas estructurales que le han dado auge al conflicto, y por supuesto el fortalecimiento de las instituciones democráticas. Aquí se destaca el papel global de la UE, es decir, la ayuda humanitaria, el involucramiento en los conflictos fuera de la región y los esfuerzos por la paz y estabilización social en el mundo, así como las tareas compartidas en términos de la gobernanza global en donde ha primado la cooperación con una visión de fortalecimiento de la fuerza y el poder miliar, que destaca el apoyo en el campo de la seguridad.

Sin embargo, los europeos, y particularmente la nación alemana, se han concentrado más en el fortalecimiento de todos aquellos derechos ciudadanos; es decir, en el empoderamiento de la sociedad civil, pero también en el impulso a reformas en el campo de la justicia. Y la promoción de redes de apoyo de actores públicos y privados que impulsan tareas de contribución en la generación de conocimiento y cultura de la paz y de reconciliación (Tarnaala, 2009, p. 5).

En este orden de ideas, en la década del 90 empezó lo que los analistas denominaron la internacionalización del conflicto de Colombia, y más adelante la internacionalización del camino a la paz. De modo que fluye la cooperación de la UE hacia Colombia en la década del 2001 con el primer laboratorio de paz para el Magdalena Medio, el cual no alentó del todo el proceso de paz sino que por el contrario incrementó la violencia y la confrontación. Estos laboratorios de paz se inscriben en la lógica de la política exterior de la UE, en el marco de sus relaciones de cooperación con Colombia, y en el convencimiento de que aquí hay vías para la construcción de opciones alternativas de la ciudadanía para enfrentar el fenómeno de conflicto armado interno, la economía del narcotráfico, las condiciones de marginalidad y pobreza, y el desplazamiento forzado. En síntesis, los laboratorios de paz en Colombia son programas coherentes con la visión europea de combatir y prevenir los conflictos enfrentando las causas estructurales que lo dinamizan, pero también las que los generan o impulsan (Pastrana, 2007a, p. 3).

De este modo, las instituciones encargadas de administrar los esfuerzos de la cooperación debieron acomodarse a las condiciones vigentes y buscar nuevas formas innovadoras de tener impactos desde una posición mucho más razonable y de entendimiento con el entorno conflictivo de las localidades.

Hoy en día, los fenómenos de paz y conflicto figuran como bloques centrales en las distintas agendas de donantes de fondos para el desarrollo de los países y, en este orden de ideas, el desarrollo se va convirtiendo en un elemento primordial de las agendas políticas de la UE. Sin embargo, desarrollo, conflicto y seguridad sí han incidido en las actitudes que la UE ha tenido hacia Colombia (Tarnaala, 2009, p. 6). 
La atención de la UE a la democracia en países en conflicto, postconflicto y transición, ha circulado en torno a denominadores comunes frente a la estabilización política y al fortalecimiento institucional, lo que, unido a la asistencia electoral, se considera a nivel global como una receta para el montaje de la democracia en países y regiones que reciben cooperación para el desarrollo.

En suma, a partir de la LJP la UE ha apoyado decididamente a organizaciones y grupos de victimas en casi todo el territorio y se han creado nuevos espacios que han dejado tensiones y preocupaciones sobre los alcances políticos de la cooperación.

Sin embargo, la UE ha venido apoyando al Gobierno en sus esfuerzos de ahondar en la justicia transicional en varios aspectos como la desmovilización, el desarme y la reintegración de los grupos paramilitares, la desmovilización de guerrilleros y el apoyo a la Comisión Nacional de Reparación y Reconciliación.

\section{Conclusiones}

En primer lugar, Alemania y Colombia han promovido compromisos de cooperación desde hace más de 50 años. Estos han sido esfuerzos comunes de las naciones encaminadas a lograr la paz y el desarrollo sostenible. Sin embargo, esto se ha reforzado a partir de 2007 con un nuevo régimen legal que ha establecido la UE para el desarrollo de las naciones, incluyendo la región de América latina, y particularmente a Colombia, dada la complejidad del conflicto armado interno, que ha generado desconfianza entre el Estado y la sociedad civil, y que necesita del apoyo y la ayuda bilateral, y multilateral de las naciones.

En segundo lugar, las naciones acosadas por la fuerza de la globalización, le apuestan también a diversos mecanismos, que facilitan la gobernanza de ciertos problemas globales, regionales, bilaterales o multilaterales, por medio del impulso a la promoción de alianzas o redes de cooperación entre actores públicos y privados. Esta es una estrategia que se multiplica en los escenarios bilaterales o multilaterales, pero también en la cooperación con otros actores que incluyen instituciones económicas, científicas y ciudadanas de los países. Esto a diferencia del papel jerárquico y de cierto modo autoritario del pasado que se agencia desde las instituciones globales. No obstante, aquí se observa el comienzo de una propuesta o de un papel negociador o mediador para enfrentar los grandes problemas de orden social y político de los países desde otra perspectiva que involucra la conceptualización de un nuevo modelo de gobernanza. En este sentido, se está obligando a recurrir a un mayor bilateralismo y multilateralismo para la solución de los problemas mundiales dado que el carácter transfronterizo implica instrumentos como la cooperación internacional para abordarlos. De este modo, el concepto de gobernanza aparece respaldado en diversos niveles de coordinación, cooperación y búsqueda de soluciones comunes en la esfera internacional.

En tercer lugar, vemos que según las experiencias alemanas de construcción de paz y consolidación democrática con procesos de justicia transicional que se adecúen a las 
disposiciones internacionales que protegen a las víctimas es posible reconstruir los tejidos sociales rotos por la violencia. Los modelos aplicados en Alemania han sido referentes transcendentales tanto para la construcción teórica de los modelos de justicia transicional como para la aplicación empírica de los presupuestos conceptuales. Igualmente, se ha demostrado que los conflictos armados y los regímenes autoritarios se pueden abordar desde los marcos políticos y normativos, que ofrece la justicia transicional y así proyectar una paz sostenible que contribuya directamente al desarrollo social y económico de cualquier nación

Por último, es evidente que Alemania ha demostrado un especial interés en aportar a la solución negociada del conflicto armado en Colombia. Así entonces, desde la aplicación de la LJP, el país alemán ha implementado una estrategia política de cooperación para una correcta ejecución normativa, lo cual ha generado la creación de muchos programas orientados a prestar asesoría y apoyo logístico promoviendo la construcción de paz y reconciliación nacional. En este sentido, para Alemania el proceso de justicia y paz en Colombia ha marcado un gran paso en la construcción de modelos que desarrollen los presupuestos teóricos de la justicia transicional, aportando así un referente importante para nuevos procesos. Finalmente, y sobre esa misma vía, Alemania denota un interés por apoyar activamente en la reconstrucción del tejido social roto por la violencia ante un eventual acuerdo de paz con las FARC.

\section{Referencias Bibliográficas}

Ambos, K. y Meyer-Abich, N. (2009). Justicia de transición. Informes de América Latina, Alemania, Italia y España. Montevideo: Konrad Adenauer Stiftung.

Añaños, C. (2008). La política exterior y seguridad Alemana bajo el gobierno de la Canciller Merkel: Entre continuidad y cambio. Un balance crítico. Revista electrónica de estudios internacionales, 16, 1-32. Disponible en: dialnet.unirioja. es/descarga/articulo/2942633.pdf

Avello, M. (2008). Esfuerzos europeos en justicia transicional. Madrid: Editorial FRIDE.

Cardona, D. (2011). Colombia: una política exterior en transición. Bogotá: Fundación Friedrich Ebert en Colombia. Disponible en: http://es.scribd.com/ doc/80552169/Colombia-una-politica-exterior-en-transicion

Centro de Estudios Políticos y Constitucionales (2006). Memoria histórica: el proceso de justicia transicional en Alemania, Argentina, Chile, España, Portugal y Sudáfrica. CEPC, 27, Disponible en: http://www.cepc.gob.es/centro-de-recursos/ documentacion/boletinesydossieresdedocumentacion/boletinesdocumentacion/ boletindocumentacion27. 
Comisión Europea (2007). Documento de estrategia país. 2007-2013. Bogotá: Editorial Comisión Europea.

Comisión Europea (2007-2013). Documento estrategia país. Marzo 28 del 2007. (E2007/484). Bogotá: Comisión Europea. Disponible en: http://www.eeas. europa.eu/colombia/csp/o7_13_es.pdf

Coalition for the International Criminal Court CCPI (2005). La Corte penal Internacional y Tribunales Penales Internacionales ad hoc. CCPI. Disponible en: http://www. iccnow.org/documents/FS-CICC-AdHocTribunals_Septo5_SP.pdf

Cuervo, J., Becerra, E. y V. Hinestroza. (2007). Justicia transicional: modelos y experiencias internacionales. A propósito de la Ley de Justicia y Paz. Bogotá: Editorial Universidad Externado de Colombia.

De Greiff, P. (2005). Reparación de víctimas en proceso de paz. En: S. Jaramillo (Ed.), Cuadernos del conflicto, justicia, verdad y reparación en medio del conflicto. Bogotá: Editorial Legis.

De Greiff, P. (2008). Justicia y reparaciones. En C. Díaz (Ed.). Reparaciones para las víctimas de la violencia política Serie de justicia transicional. Bogotá: Fondo global para la pazy seguridad del Ministerio de Relaciones Exteriores de Canadá.

Del Arenal, C. (2008). Mundialización, creciente interdependencia y globalización en las relaciones internacionales. Madrid: Universidad Complutense.

Delegación de la Unión Europea para Colombia (2009). Directrices en materia de derechos humanos. Bogotá: Géminis.

Díaz, C. (2008). Reparaciones para las víctimas de la violencia política. Estudios de caso y análisis comparado. Bogotá: Fondo Global para la paz y seguridad del Ministerio de Relaciones Exteriores de Canadá.

DW.DE. (10 de mayo de 2013). Gauck: Alemania ve con respeto el proceso de paz para Colombia. ). Disponible en: http://www.dw.de/gauck-alemania-ve -con-respeto-el-proceso-de-paz-para-colombia/a-16805867

Embajada de la República Federal de Alemania (2007). Creamos juntos la cooperación alemana para el desarrollo en Colombia. Bogotá: ERFA.

Embajada de la República Federal de Alemania (2011). Juntos creando el futuro. Bogotá: ERFA.

Forer, A. (2011). Colombia: un nuevo modelo de justicia transicional. Bogotá: ProFis.

Grupo Sur (2008). Abriendo todas las puertas de la UE a las mujeres. Bruselas: Oxfam-Solidarité. 
Hintereder, P. (2013). Actualidad de Alemania. Disponible en: http://www.tatsachenueber-deutschland.de/es/politica-exterior.html

Human Rights Watch (29 de octubre de 2005). Recomendaciones para decretos reglamentarios de ley 975 de 2005. Publicaciones informes sobre Colombia. Disponible en: http://www.hrw.org/es/reports/2005/10/29/recomendaciones-de-humanrights-watch-sobre-el-decreto-reglamentario-de-la-ley-97.

López, C. y Vargas, A. (2009). Manual de procedimiento para la Ley de Justicia y Paz en Colombia. Bogotá: ERFA.

Ministerio de Agricultura y Desarrollo Rural (2012). Informe trimestral. Unidad de Restitución de Tierras. Bogotá: MADR.

Ministerio de Asuntos Exteriores y cooperación Española (2012). Estrategia multilateral de cooperación española para el desarrollo. Madrid: Editorial Ministerio de Asuntos Exteriores y Cooperación. Disponible en: http://www.exteriores.gob. es/Portal/es/PoliticaExteriorCooperacion/CooperacionAlDesarrollo/Paginas/ Planificaci\%c3\%b3n.aspx

Morata, F. (2004). Gobernanza multinivel en la Unión Europea. Valencia: Guada Impresores.

Oficina Internacional de Derecho Humanos - Acción Colombia (OIDHACO) (2009). Cooperación de la UE en Colombia. Disponible en: http://www.oidhaco.org/ uploaded/content/category/1343734273.pdf

Oddone, N. (2013). La integración regional y cooperación transfronteriza en los nuevos escenarios de América Latina. Santa Marta: Editorial Universidad del Norte. Disponible en:http://rcientificas.uninorte.edu.co/index.php/investigacion/issue/view/331

Organización de las Naciones Unidas (OACNUDH) (2005). Derechos humanos una herramienta para el cambio. Bogotá: ONU. Disponible en: http://www.hchr. org.co/sobrenosotros/sobrenosostros.php3

Orozco, C. (2009). Justicia transicional en tiempos del deber de memoria. Bogotá: Temis.

Ospina, J. (2013). ¿Paz en Colombia? Alemania aporta a su búsqueda. DW. Disponible en: http://www.dw.de/paz-en-colombia-alemania-aporta-a-su-b\%C3\% basqueda/a-16801895

Pastrana, E. (2005). Extinción o reinvención del estado nación frente a los desafíos globales. Desafios, 12, 282-285.

Pastrana, E. (2006). Las Relaciones Colombia-Unión Europea: entre luces y sombras. Bogotá: Fescol. 
Pastrana, E. (2007a). La Unión Europea como potencia civil: la estrategia de los laboratorios de paz en Colombia. En: Decanatura académica facultad de ciencia política y relaciones internacionales (Ed.), Memorias del II Coloquio de profesores de la Facultad de Ciencia Política y Relaciones Internacionales. Bogotá: Editorial Pontificia Universidad Javeriana.

Pastrana, E. (2007b). La Unión Europea frente a la Ley de Justicia y Paz y la desmovilización de las AUC: entre las dudas y el pragmatismo. Bogotá: Fescol.

Pastrana, E. (2011). Elfuturo de las relaciones entre Colombiay la Unión Europea: profundización o estancamiento. Bogotá: Friedrich Ebert Stiftung. Disponible en: http:// es.scribd.com/doc/80552169/Colombia-una-politica-exterior-en-transicion

Pastrana, E. y Aponte D. (2006). La Unión Europea como potencia civil: la estrategia de los laboratorios de paz en Colombia. Revista Diálogos y saberes, 25, 241-279.

Pardo, R. (2001). Revista Colombia Internacional. Facultad de Ciencias Sociales. Departamento de Ciencia Política, 51, enero-abril. Disponible en: http://colombiainternacional.uniandes.edu.co/view.php/378/view.php

Quevedo, J. (2009), El Interregionalismo Unión Europea- América Latina y el Caribe: claves para la construcción de un sistema multilateral. Departamento de Estudios Internacionales de la Universidad de Guadalajara. Disponible en: www. interscienceplace.org/interscienceplace/article/download/19/24

Quiroga, Martha Lucia. (2010). Alemania: continuidad, rupturas y desafíos de su política exterior desde 1990. Disponible en http://www.redalyc.org/ pdf/531/531214590o8.pdf

Ramírez, S. (2011). El giro de la política exterior colombiana. Revista Nueva Sociedad, 231, enero-febrero, Disponible en: http://wwww.nuso.org/upload/articulos /3754_1.pdf

Rouquayrol, L. y Herrero, S. (2007) Guía sobre la cooperación UE - América Latina. Francia: Editorial EuropeAid. Disponible en: http://ec.europa.eu/europeaid/where/ latin-america/regional-cooperation/documents/guidecooperation_eu_la_es.pdf

Schunemann, J. (2006). Cooperación internacional e interregionalismo: una aproximación social constructivista. Madrid: Editorial ICEI.

Simmons, O. O. (2013). Colombia frente a la integración infraestructural suramericana: una aproximación a su papel en la IIRS. Bogotá: Editorial Pontificia Universidad Javeriana. 
Sikkink, K, Frey, B. y Luons, A. (2010). Reporte Temático de política exterior colombiana: derechos humanos y derecho internacional humanitario. En: S. Borda et al (Eds.). Misión de la política exterior colombiana (pp. 459-520). Bogotá: Universidad de los Andes.

Tarnaala, E. (2009). Paz y democracia. Cómo evaluar el impacto de la ayuda europea en Colombia. Redintercol. Bogotá: Universidad Externado de Colombia. Disponible en: http://www.redintercol.org/Tarnaala-Elisa-Paz-democracia.pdf

Tokatlian, J. y Pardo, R. (1987). Relaciones Exteriores y Política Interna. En: Política Exterior Colombiana (pp. 113-154). Bogotá: Editorial Tercer Mundo.

Tokatlian, J. y Pardo, R. (1988). Política exterior colombiana ¿De la subordinación a la autonomía? Bogotá: Tercer Mundo Editores/Ediciones Uniandes

Teittel, R. (2003). Transitional Justice Genealogy. Harvard Human Rights Journal, $16,69-94$.

Uprimny, R. (2005). Justicia transicional y justicia restaurativa: tensiones y complementariedades. Bogotá: Universidad de los Andes.

Valdivieso, A. (2012). La justicia transicional en Colombia: Los estándares internacionales de Derechos Humanos y Derecho Internacional Humanitario en la política de Santos. Papel Político, 17 (2), 573-616. 